\title{
Student Attitudes \\ On Academic Integrity Violations
}

Russell K. Baker, (Email: rbaker1@ju.edu), Jacksonville University

Priscilla Berry, (Email: pberry1@ju.edu), Jacksonville University

Barry Thornton, (Email: bthornt@ju.edu), Jacksonville University

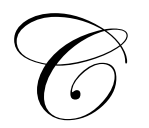

heating is a continual dilemma on university campuses, and academic integrity violations have reached epidemic proportions according to current literature. In 1990, the American Council on Higher Education reported that cheating was increasing, and this trend was expected to continue (Nowell, 1997). Studies throughout the 1990s confirmed this trend, revealing that up to 75 percent of college students had cheated sometime during their college careers, many on a regular basis (Koch, 2000). The rapid growth of computer technologies and their application in education has provided unethical students, and otherwise ethical students, with new tools for their cheating activities. In 1999 at the University of Edinburgh, 117 freshman students were implicated in the largest computer cheating investigation in the United Kingdom. The students were discovered using e-mail to exchange test answers during an examination. By using plagiarism-detection software and examining internal e-mail records, university officials verified students had transmitted answers to each other (Wilson, 1999). In 2000, Northeastern University in Boston experienced an incident during which 30 engineering students copied computer-based homework assignments from each other. The students were required to complete assignments on computers for an Engineering Physics course. One student completed the assignment and verified its accuracy. Subsequent students copied the previous student's work into their own file. The 30 cheaters submitted identical answers, which had been obtained by exchanging computer files (DiCesare, 2000).

While extensive research exists on academic integrity violations in higher education, there is a limited body of research on students' attitudes as to what constitutes academic integrity violations. Additionally, the authors found no research comparing student propensities to cheat, when they believe what they are doing is cheating, versus their propensities to cheat, when they believe the practices they are engaged in are not cheating. The purpose of this paper is derived from the necessity to address the issue of what students consider cheating.

\section{PURPOSE OF STUDY}

The purpose of this study is to assess college students' perceptions on the level of seriousness of academic integrity violations.

\section{EDUCATIONAL SIGNIFICANCE}

The effects of academic integrity violations in academia are detrimental to institutions of higher education. The impact of academic violations occurring within an academic institution creates a breakdown in multiple systems of the institution. The concept that cheating begets cheating is substantiated by several studies (Baker \& Papp, 2003). Students, who believe that when others get away with cheating their academic standing is affected, may themselves cheat to compete for grades. Universities that are unable to control cheating risk both their reputations and accreditations (Baker \& Papp, 2003). Consequently, it is imperative that educational institutions understand and control academic integrity violations.

\section{THEORETICAL FRAMEWORK}

The research questions presented herein are based on two theoretical positions. First, students understand the nature of academic integrity violations and recognize that committing academic integrity violations in educational institutions is unacceptable student behavior. Second, a relationship exists between student attitudes on cheating and the student belief that specific practices are either not cheating or cheating of a non-serious nature. 
Finally, student perceptions and attitudes, regarding the seriousness of committing these similar but distinct types of academic integrity violations, correspond with their actions.

\section{HYPOTHESES}

The following three null hypotheses and corresponding alternative hypotheses are forwarded for this study:

H1o: College students do not understand what constitutes the scope of academic integrity violations.

H1a: College students do understand what constitutes the scope of academic integrity violations.

H2o: $\mu \mathrm{b} 1=>\mu \mathrm{b} 2$, College students are equally prone to commit academic integrity violations when they believe an activity constitutes an academic integrity violation as they are when they do not believe an activity constitutes an academic integrity violation.

H2a: $\quad \mu \mathrm{b} 1<\mu \mathrm{b} 2$, College students are less prone to commit academic integrity violations when they believe an activity constitutes an academic integrity violation as they are when they do not believe an activity constitutes an academic integrity violation.

H3o: $\mu 1>\mu 2$, College students are more prone to commit plagiarism academic integrity volitions when computer technologies are part of an assignment / test than when computer technologies are not used for an assignment / test.

H3a: $\quad \mu \mathrm{c} 1<=\mu \mathrm{c} 2$, College students are not more prone to commit plagiarism academic integrity volitions when computer technologies are part of an assignment / test than when computer technologies are not used for an assignment / test.

\section{DELIMITATIONS OF THE STUDY}

The study has several delimitations. First, the study is restricted to an analysis of student attitudes towards academic integrity violations. Secondly, the study is restricted to undergraduate students enrolled in a midsize private, southern, urban university. Finally, the study is not intended to be generalized to other students or student body populations.

\section{LIMITATIONS OF THE STUDY}

Limitations for this study include threats to external and internal validity. In the research design/data collection, data analysis, and data interpretation stages the following threats to internal and external validity were noted (Onwuegbuzie, 2003). The limited demographic characteristics of the surveyed population make it difficult to generalize findings to a larger targeted population of individuals. The study was conducted in a medium-sized metropolitan university in the southeastern United States; this regional attribute may make it difficult to generalize to a larger targeted population of individuals.

Prior research indicates that academic dishonesty has consistently existed over a significant period. However, there is little evidence that academic violation findings can be generalized across time. Specificity of variables is another threat to validity because the circumstances, individuals, and outcome variables were specific to this place and time and may not be capable of being generalized. The potential for Type I to Type X error exists in this study (Onwuegbuzie, 2003, Daniel and Onwuegbuzie, 2000).

\section{LITERATURE REVIEW}

Academic dishonesty has been a consistent problem for educators for generations. Drake (1941) reported over sixty years ago, "Students in general have no strong sentiments against classroom cheating and will not cooperate to control it" (420). Research, attempting to find correlations between various demographic characteristics of students and the propensity to engage in academic dishonesty, has been ongoing during much of this sixty-year time frame. Research by Parr (1936) and Drake (1941), who engaged in extensive analyses of academic integrity issues prior to World War II, resulted in numerous findings. Students who graduated in the upper one-third of their class were far more honest than those who ranked in the middle and lower thirds (Parr, 1936). The percentage of 
cheating increases with an increase in the other-than- academic activities in which the student participates. Parr (1936) found 36 percent of students participating in one activity cheated, and this compared with 57 percent found cheating of those participating in four or more activities. Parr (1936) reported that students become less dishonest as they progressed in their education. Freshman academic violations were reported to be 33 percent higher than sophomores' violations. Furthermore, a strong relationship exists between academic standing and student dishonesty. Parr (1936) reports 18 percent of A students cheat, 35 percent of B students, 44 percent of C students, and 58 percent of D students. This is confirmed by Drake's (1941) study that reported no cheating by A students, 4 percent $\mathrm{B}$ students engaged in cheating, 23 percent of $\mathrm{C}$ students, 75 percent of $\mathrm{D}$ students, and 67 percent of $\mathrm{F}$ students. Drake reported a correlation between intelligence-test scores and cheating instances. Of 30 students who engaged in cheating during a test activity, none were in the highest quarter scores on intelligence test, nine were in the second quarter, six in the third quarter, and 15 in the fourth quarter.

Demographic co-relational research continued to be the dominant focus of academic-integrity research through the second half of the twentieth century and into the twenty-first century. Kelly and Worrell (1978) reported students committing academic integrity violations are of a lower ability than their peers, and consequently under pressure to compete with more capable students. Additionally, if other students are known to be cheating, the lowerability non-cheater may feel at a disadvantage (McCabe \& Trevino, 1993). Other research found a positive relationship exists between the need for social approval and cheating because of students' need to be considered academically successful (Davis, Grover, Becker, \& McGregor, 1992),

\section{METHODOLOGY}

This comparison study is intended to evaluate and compare student attitudes towards activities that constitute academic dishonesty. The following discussion addresses the participants, instrument, and procedures that comprise the study. The instrument and study proposal have been reviewed and approved by the Institutional Review Board at the university when the survey was administered.

The pilot instrument (see appendix) is a digitally- administered, forty-five question survey. The instrument is administered using the survey feature in Blackboard ${ }^{\circledR}$. A Blackboard survey allows respondents to complete the questionnaire online in absolute confidentiality. The user ID of each respondent is recorded by the Blackboard system, as are the responses, but no correlation is possible between user ID and responses. Data collected for responses to individual questions include the number of total responses and the percent of each possible response.

The Blackboard survey was pilot-tested using approximately eighty student respondents. The pilot test was designed to both evaluate the clarity of individual questions and provide preliminary response direction to the researchers. This would enable adjustment of the methodology and questionnaire if needed. Pretest results are provided herein.

The Blackboard survey capability is limited. Correlation between Likert-scale attitudinal responses and demographic-information responses is not possible within this tool thereby limiting its effectiveness. Consequently, Blackboard was used only for pilot testing attitudinal responses. The complete survey will be submitted using another software technology that has yet to be determined.

All participants will receive the same digital survey instrument. Quantitative questions regarding computer technologies are interspersed within the questionnaire to ascertain if differences in student attitudes and perceptions exist between circumstances that utilize computer technologies and those that do not. Respondents select their response by clicking a radio buttons adjacent to their selection.

\section{PARTICIPANTS}

The student body of a midsize private, southern, urban university was selected for testing. The student body consists of approximately 3500 undergraduate and graduate students in multiple fields of study. The university 
is principally a liberal arts and sciences institution. Approximately one-fourth of the undergraduate population is in the school of business. The student body is multicultural and multiracial.

\section{TERM DEFINITIONS}

- $\quad$ Academic Integrity Violation: Cheating. Violating the academic integrity policies of the university.

- $\quad$ Cheating: to violate rules dishonestly as at cards or on an examination (Merriam-Webster Online Dictionary, 2005). Violation of the written or verbal requirements established for an assignment or examination.

- $\quad$ Fabrication: The creation of data and/or information without basis in fact.

- Minor Cheating: an academic integrity violation sufficiently serious to merit a point reduction on an assignment or examination but no additional punitive action.

- Moderate Cheating: an academic integrity violation sufficiently serious to merit the student failing the assignment but no additional punitive action.

- Not Cheating: an activity that does not constitute an academic integrity violation.

- Plagiarism: "the use of someone else's words or ideas without an appropriate acknowledgement" (Catalog, 2004). "To steal and pass off (the ideas or words of another) as one's own: use (another's production) without crediting the source.

- To commit literary theft: present as new and original an idea or product derived from an existing source" (Merriam-Webster Online Dictionary, 2005).

- $\quad$ Prevarication: Lying about an examination or assignment to receive unmerited benefit or advantage.

- $\quad$ Serious Cheating: an academic integrity violation sufficiently serious to merit the student failing the course and being reported to the university's academic counsel for disciplinary action.

\section{DISCUSSION OF SURVEY RESULTS}

The authors classified the pre-test survey questions into categories. Initially, the questions were divided into two super-ordinate categories reflecting whether the incident questioned involves using computer technologies or non-computer/paper instruments. Consequently, the initial two categories are computerized and noncomputerized. The computerized category was restricted to those activities that are not possible without the aid of computer technologies. Consequently, purchasing a paper from a website is a computerized activity while purchasing a paper from another student is viewed as using a non-computer technology. The website purchase requires computer technology use while another student may provide a hand-written paper.

Subsequently these two categories were subdivided into the following categories:

- Plagiarism: any activity that a student engages in which may be construed as an academic integrity violation that involves the incorporation of another's words, ideas, or concepts without properly acknowledging that author within the context of the student's document. See plagiarism in the definitions section

- $\quad$ Testing: any activity that a student engages in which may be construed as an academic integrity violation during or associated with an examination, test or quiz.

- $\quad$ Fabrication/Prevarication: any activity that a student engages in which may be construed as an academic integrity violation and involves the false creation of data and/or information, lying about an assignment or examination to achieve unmerited additional credit, failure to fully disclose relevant facts which results in a misinterpretation on the part of an instructor, or the willful destruction or concealment of academic materials to prevent other students from accessing it.

- Unclassified cheating: any potential academic integrity violation not encompassed by one of the aforementioned categories.

Dividing the questions into these categories provides the matrix for question evaluation and comparison displayed in Table 1. 
Table 1 - Pre-test survey question categories:

\begin{tabular}{|c|c|c|}
\hline & Computerized & Non-computerized \\
\hline Plagiarism & & \\
\hline Testing & & \\
\hline Fabrication/Prevarication & & \\
\hline Unclassified cheating & & \\
\hline
\end{tabular}

Categorizing the survey questions in this manner provides several venues for analysis and comparison of responses. The most obvious is a comparison of student attitudes as it relates to computerized and non-computerized cheating. Second, comparisons may be made of student attitudes towards academic integrity violations among the various subordinate categories, within each of the super-ordinate categories. Finally, student responses, within each of the subordinate categories, may be compared to evaluate if students view different types of activities, within a subordinate category, as more or less serious as other activities within that category. Table 1 (with the pre-test survey questions assigned to categories within the table) is in the appendix. Questions one and 2 are generalinformation questions and are not assigned to categories.

\section{DATA ANALYSIS}

H1o: College students do not understand what constitutes the scope of academic integrity violations.

The authors, to determine if students recognize academic integrity violations and their level of seriousness, performed a subjective evaluation of pre-test results. The aggregate data in the four categories: Plagiarism, Testing, Fabrication/Prevarication, and Unclassified were examined and compared across groups. Of the students surveyed in the category of plagiarism, $58 \%$ believe it to be a non-serious academic violation to submit another student's work as their own, to purchase a term paper, or to write a paper for another student. Further, this data set shows the same $58 \%$ of students find it not serious cheating to copy a few sentences from a book without citing, to copy and paste from another student's paper, or to copy and paste from the internet.

\begin{tabular}{|c|c|}
\hline Plagiarism & Average \\
\hline Not Cheating & $6.18 \%$ \\
\hline Minor Cheating & $22.81 \%$ \\
\hline Moderate Cheating & $28.57 \%$ \\
\hline Serious Cheating & $42.11 \%$ \\
\hline \multicolumn{2}{|l|}{ Testing } \\
\hline Not Cheating & $14.12 \%$ \\
\hline Minor Cheating & $23.54 \%$ \\
\hline Moderate Cheating & $26.18 \%$ \\
\hline Serious Cheating & $35.82 \%$ \\
\hline \multicolumn{2}{|c|}{ Fabrication/Prevarication } \\
\hline Not Cheating & $25.37 \%$ \\
\hline Minor Cheating & $26.04 \%$ \\
\hline Moderate Cheating & $21.56 \%$ \\
\hline Serious Cheating & $27.03 \%$ \\
\hline \multicolumn{2}{|l|}{ Unclassified Cheating } \\
\hline Not Cheating & $47.76 \%$ \\
\hline Minor Cheating & $22.39 \%$ \\
\hline Moderate Cheating & $19.40 \%$ \\
\hline Serious Cheating & $10.45 \%$ \\
\hline
\end{tabular}


In the testing category, including both computerized and non-computerized questions, $65 \%$ of students consider not serious such academic violations as the following:

- $\quad$ Changing answers on a graded test to raise the score

- $\quad$ Cheating on a computerized test

- $\quad$ Looking at another student's monitor

- $\quad$ Copying from another student's work without their knowledge

- $\quad$ Helping another student cheat

- $\quad$ Using crib notes or taking and using computer help during an exam

An evaluation of the Fabrication/Prevarication category revealed that $73 \%$ of students consider not serious such academic violation as the following:

- Damaging library materials,

- $\quad$ Fabricating a reference list

- $\quad$ Failing to list all sources in a reference list

- $\quad$ Falsifying lab results or research data,

- $\quad$ Misquoting a source intentionally

- $\quad$ Lying about due dates or lying to receive undeserved credit

From the survey questions in the unclassified categories of cheating, $90 \%$ of students consider not serious cheating the following range of actions:

- $\quad$ Failing to contribute a fair share to a group project or letting others do more work

- $\quad$ Failing to use assigned format

- $\quad$ Receiving unauthorized help on an assignment

- $\quad$ Sharing an assignment for others to us as an example

- Working on an assignment for others without authorization

Table 4 displays the average student responses for each of the four categories evaluated.

H2o: $\quad \mu \mathrm{b} 1=>\mu \mathrm{b} 2$,

College students are equally prone to commit academic integrity violations when they believe an activity constitutes an academic integrity violation, as they are when they do not believe an activity constitutes an academic integrity violation.

A preliminary evaluation of hypothesis two based on pre-test results was not performed.

H3o: $\quad \mu 1>\mu 2$,

Initially, this study compared student attitudes to computerized and non-computerized testing and plagiarism considering the definitions as outlined in the Term Definitions, see page 9. Questions related to activities of similar academic integrity violation are paired to provide a direct comparison for similar activities utilizing computer technologies and using non-computer technologies. Three pairs of questions will be examined in the computerized plagiarism versus non-computerized plagiarism categories, and three pairs of questions will be examined in the computerized testing versus non-computerized testing categories. The following paired questions will be analyzed: 
- $\quad$ Pair One (plagiarism):

Questions 35 - Submitting a paper acquired in whole or part from a Website that did not charge for this information

Question 36 - Submitting an assignment done by someone else as your own

- $\quad$ Pair Two (plagiarism):

Question 6-Copying a few sentences from a book source without quotes

Question 7 - Copying a friend's spreadsheet, PowerPoint, database or other computerized assignment

- $\quad$ Pair Three (plagiarism)

Question 11 - Cutting and pasting another student's work into yours

Question 40 - Turned in an assignment copied from another in whole or part

- $\quad$ Pair Four (plagiarism)

Question 9 - Copying material word for word from a written source without quotes and crediting the source

Question 12 - Cutting and pasting from an internet source without quotes or citing the source

- $\quad$ Pair Five (plagiarism)

Question 34 - Buying a term paper from a website.

Question 3 - Buying a term paper from another student.

The comparisons of these pairs and the overall values are accomplished using the two-sample test of proportions based on the following hypothesis:

$H_{0}: \Pi_{1}=\Pi_{2}$ the null hypothesis (non-computerized equals computerized)

$H_{A}: \Pi_{1} \neq \Pi_{2}$ the alternate hypothesis

The null hypothesis makes the following statement: the two samples come from populations where the proportions of students responding with response number 4 (serious cheating) to the questions are the same. The alternate hypothesis says the proportions are different. The tests will be done 2 tailed, and using the five percent level of significance: $\alpha=.05$. Since the sample sizes are large $(\mathrm{n}=57)$, a $\mathrm{z}$ test is used.

$$
z=\frac{p_{1}-p_{2}}{\sqrt{\frac{\left(p_{c}\right)\left(1-p_{c}\right)}{n_{1}}+\frac{\left(p_{c}\right)\left(1-p_{c}\right)}{n_{2}}}}
$$

- $\quad p_{1}=$ the proportion in sample 1 (computerized plagiarism sample) that responded to the question with response number 4 (serious cheating).

- $\quad p_{2}=$ the proportion in sample 2 (non-computerized plagiarism sample) that responded to the question with response number 4 (serious cheating).

- $\quad p_{c}=$ the pooled (combined) proportion, which is a weighted average of $p_{1}$ and $p_{2}$

- $\quad$ Since the sample sizes are the same, $n_{1}=n_{2}=57$

The following are the test results for the paired questions and the overall summary. The test for paired questions thirty-four and three is provided in its entirety to demonstrate the evaluation process used. The test results for other paired questions and overall results are summarized.

Test 1 - Questions 34 (sample 1) and 3 (sample 2)

$$
H_{0}: \Pi_{1}=\Pi_{2} \quad H_{A}: \Pi_{1} \neq \Pi_{2} \quad \alpha=.05
$$


The computed value of the test statistic (using the $\mathrm{z}$ formula above) is -1.6357 (this formula takes all the information from the two samples and combines into one number - this is the evidence from the sample).

- Decision Rule: If the computed value of the test statistics is greater than 1.96 or less than -1.96 , reject the null hypothesis.

- $\quad$ Conclusion: Do not reject the null hypothesis - the sample evidence suggests that there is no significant difference in the proportion of the computer and non-computer plagiarism students who responded 4 to the question.

- $\quad \mathrm{p}$-value - what is the lowest level of significance at which we would reject the null - for this test, p-value is 0.10

\section{Test 2: Questions 7 and 6}

Computed value of test statistic is 0 . p-value is 1 . Do not reject, look to test 1 for explanation.

\section{Test 3: Questions 11 and 40}

Computed value of test statistic is 1.2865. p-value is 0.197. Do not reject.

\section{Test 4: Questions 12 and 9}

Computed value of test statistic is -2.2305 . p-value is 0.0258 . Reject the null hypothesis. The sample evidence suggests that a significantly smaller proportion of the computer group responded 4 to this question.

\section{Test 5: Questions 35 and 36}

Computed value of test statistic is 0.1591 . p-value is 0.8728 . Do not reject.

\section{Test 6: Overall}

Computed value of test statistic is -0.6428 . p-value is 0.5222 . Do not reject.

\section{CONCLUSIONS}

Based on preliminary analysis of the pre-test data, the students surveyed lack an understanding of the seriousness of many academic integrity violations, and present no clear understanding of what constitutes an academic violation. Approximately sixty-six percent of the student responding indicated that, based on aggregate category data, cheating during testing is not serious. Anecdotally, faculty who were questioned indicated all of the survey questions related to testing to be serious infractions of academic integrity violations. However, it would be helpful, from a co- relational view, to survey faculty to ascertain the correlation between faculty attitudes based on empirical survey responses and the student attitudes reflected herein.

- The analysis of the computerized versus non-computerized data, related to testing, indicates that there is not a statistically significant difference in student attitudes towards academic integrity violations in either venue. However, a statistically significant difference exists in students' responses related to copy-and-paste plagiarism in computerized versus non-computerized circumstances. Students do not believe that copy-andpaste plagiarism, when using computer technologies, is as serious an issue as copying from literature without citing, when computer technologies are not used.

\section{RECOMMENDATIONS}

The complete survey, including demographic questions, should be presented to a larger population of students. This will either help to support (or refute) the conclusions drawn herein and will provide rich data for 
demographic analysis of specific questions. Additional question pairs related to computerized versus noncomputerized academic integrity violations should be incorporated into the instrument to provide a broader base for this analysis. Finally, faculty should be surveyed to determine if there is a correlation between faculty attitudes and student attitudes regarding academic integrity violations.

\section{REFERENCES}

1. Baker, R. (2003). Digital academic dishonesty. Proceedings of the Hawaii International Conference on Education, Honolulu, HI.

2. Baker, R., \& Papp, R. (2003). Academic integrity violations in the digital realm. Proceedings of the Southern Association for Information Systems Conference, Savannah, GA.

3. Blackboard. (n.d.). Blackboard homepage. Retrieved January 6, 2002, from http://www.blackboard.com.

4. DiCesare, Frank. (April 11, 2000). Thirty Students Accused of cyber-cheating. Northeastern University. Retrieved September 30, 2006, from http://www.whatsnew.neu.edu/cheating000411.html

5. Daniel, L., \& Onwuegbuzie, A. (2000, November). Toward an extended typology of research errors. Paper presented at the annual conference of the Mid-South Educational Research Association, Bowling Green, KY.

6. Davis, S., Grover, C., Becker, A., \& McGregor, I. (1992). Academic dishonesty: prevalence, determinants, techniques, and punishments. Teaching of Psychology 19, 16-20.

7. Drake, C. (1941). Why students cheat. Journal of Higher Education, XII (8), 418-42.

8. Eisenberger, R., \& Schank, D. (1985). Personal work ethic and effort training affect and Social Psychology cheating. Journal of Personality 49, 520-528.

9. Jacksonville University. Jacksonville University Catalog (2004-2005). Jacksonville, Florida.

10. Johnson, B., \& Turner, L. (2003). Data collection strategies in mixed methods research. In A. Tashakkori \& C. Teddlie (Eds.), Handbook of mixed methods in social \& behavioral research (pp. 298-299). Thousand Oaks, CA: Sage.

11. Kelly, J. A. \& Worrell, L. (1978). Personality Characteristics, Parent Behaviors, and Sex of the Subject in Relation to Cheating. Journal of Research in Personality, 12, 179-188.

12. Koch, K. (2000). Cheating in schools, CQ Researcher, 10(32), 747-57.

13. Lester, M., and Diekhoff, G. (2002). A Comparison of Traditional and Internet Cheaters. Journal of College Student Development, 43(6), 906-911.

14. May, K., \& Loyd, B. (1993). Academic dishonesty: The honor system and students' attitudes. Journal of College Student Development, 34(2), 125-129.

15. Merriam-Webster Online. (2005). Merriam Webster, Inc. [Electronic Version].

16. McCabe, D., \& Bowers, W. (1994). Academic dishonesty among males in college: A thirty year perspective. Journal of College Student Development 35(1), 5-10.

17. Mccabe, D., \& Trevino, L. (1993). Academic Dishonesty: Honor Codes and Other Contextual Influences. Journal of Higher Education, 64(5), 522-538.

18. Mcmurtry, K. (2001). E-Cheating: Combating a $21^{\text {st }}$ Century Challenge, T.H.E. Journal, 29(4), 36-41.

19. Nowell, C., \& Laufer, D. (1997). Undergraduate Student Cheating In the Fields of Business and Economics. The Journal of Economic Education, 28, 3-12.

20. Onwuegbuzie, A. (2003) Expanding the framework of internal and external validity in quantitative research. Research in the Schools, 10(1), 71-89.

21. Parr, F. W. (1936). The Problem of Student Honesty. The Journal of Higher Education, 7(6), 318-326.

22. Plowman, T. S. (2000). Academic Integrity and Informational Technology. Tech Trends, 44(1), 24-30.

23. Tibbets, S. (1999). Differences between women and men regarding decisions to commit test cheating. Research in Higher Education, 40, 323-342.

24. Wilson, R. (1999). Colleges urged to better define academic integrity and to stress its importance, Chronicle of Higher Education, 46(8), A18.

\section{APPENDIX}

The appendix may be viewed at: http://users.ju.edu/rbaker1/academicintegrityappendix.doc 
NOTES 